\title{
TK 'Aisyiyah Busthanul Athfal Tertua Dan Terbaik di Provinsi Lampung: Sebuah Tinjauan Awal
}

\author{
Bobi Hidayat ${ }^{1}$, Kuswono ${ }^{1}$, Ragil Agustono ${ }^{1}$, Umi Hartati ${ }^{1}$ \\ Pendidikan Sejarah Universitas Muhammadiyah Metro \\ Jalan Ki Hajar Dewantara no 116 Kota Metro \\ email : hidayat_bobi@yahoo.com
}

Received 27 May 2019; Received in revised form 28 June 2019; Accepted 24 August 2019

\begin{abstract}
Abstrak
Tujuan penilitian ini adalah ingin mengetahui secara historis apa yang menjadi latarbelakang pendirian TK 'Aisyiyah Bustanul Athfal tertua dan terbaik di Provinsi Lampung. Selain itu yang ingin dipaparkan dalam penulisan artikel hasil penelitian ini adalah bagaimana strategi yang digunakan oleh sekolah untuk mempertahankan keberadaan sekolah hingga saat ini dan menjadi TK 'Aisyiyah unggulan di Provinsi Lampung. Penelitian ini menggunakan metode penelitian historis dengan menggunakan 4 langkah yaitu 1). Heuristik, 2). Kritik sumber, 3). Interpretasi, dan 4). Historiografi. Hasil penelitian menunjukkan bahwa TK 'Aisyiyah Bustanul Athfal tertua di Provinsi Lampung yaitu TK 'Aisyiyah Bustanul Athfal Teluk Betung Selatan yang berdiri pada tahun 1955. Sedangkan TK 'Aisyiyah Bustanul Athfal terbaik di Provinsi Lampung yaitu TK 'Aisyiyah Bustanul Athfal 1 Pringsewu yang berdiri pada tahun 1961. Untuk mempertahankan eksistensi TK, TK 'Aisyiyah Bustanul Athfal melibatkan masyarakat khususnya anggota 'Aisyiyah dan masyarakat umum lainya dalam menajalankan kegiatan di TK baik dalam hal tenaga pengajar, sumbangan dana dan pengembangan program-program kerja lainya.
\end{abstract}

Kata kunci: Historis, Lampung, dan TK ‘Aisyiyah Bustanul Athfal

\begin{abstract}
The purpose of the research is to know the historical background of 'Aisyiah Bustanul Athfal Kindergarten establishment, the oldest and the best school in Lampung Province. Furthermore, this research wants to explain about the strategies that are used by the school to maintain its existence and can be a superior 'Aisyiah Kindergarten in Lampung Province. The research used historical research method with four steps; namely 1) Heuristic, 2) Source criticism, 3) interpretation, and 4) historiography. The result of the research showed that the oldest 'Aisyiah Bustanul Athfal Kindergarten is 'Aisyiah Bustanul Athfal Kindergarten in South Teluk Betung which was built in 1955. While the best 'Aisyiah Bustanul Athfal Kindergarten in Lampung Privince is 'Aisyiah Bustanul Athfal Kindergarten 1 Pringsewu that is builtin 1961. In order to maintain its existence, 'Aisyiah Bustanul Athfal Kindergarten involves the society especially 'Aisyiah members and other society to run the kindergarten's activities such as teacher, funds donation and other programs development.
\end{abstract}

Keywords : historical, Lampung and 'Aisyiah Bustanul Athfal Kindergarten

\section{PENDAHULUAN}

Perkembangan zaman dan kemajuan suatu bangsa tidak terlepas dari regenerasi pemudanya yang dibangun baik oleh bangsanya. Pembangunan yang dilakukan tidak terlepas dari pembentukan pemuda yang berkualitas tinggi. Hal ini perlu dilakukan dengan tujuan untuk menjaga eksistensi bangsa dalam menghadapi tantangan perkembangan zaman yang semakin kompleks. Kenyataan yang ada pada pemuda saat ini merupakan proyeksi pendahulu kita dalam mempersiapkanya. Selain itu, tugas saat 
ini adalah menyiapkan generasi mendatang sedini mungkin agar dimasa yang akan datang, pemuda dapat menghadapi berbagai tantangan zaman yang semakin berat guna tetap terus menjaga dan meneruskan cita-cita luhur bangsa Indonesia.

Tantangan bangsa yang mulai harus dihadapi semisal globalisasi. Globalisasi memberikan perubahan manusia dewasa ini bukan hanya tata cara kehidupan dalam bidang ekonomi, tetapi juga didalam bidang sosial, budaya, dan politik (H.A.R. Tilaar, 2012:64). Selain itu, ideologi bangsa saat ini juga dihadapkan dengan tantangan yang berat yaitu upaya penggantian ideologi bangsa dengan ideologi yang lain. Pemuda juga dihadapkan dengan tantangan sosial kemanusiaan. Dimana tatanan keluarga semakin lemah dampak sibuknya orang tua memenuhi tuntutan kebutuhan hidup. Dunia virtual yang mulai nampak geliatnya juga menjadi tantangan tersendiri generai muda sekarang dan generasi mendatang.

Tantangan besar lainya adalah dampak psikologis berupa depresi dan stres yang juga diprediksi akan muncul di masa yang akan datang. Hal inilah yang menjadi perhatian serius agar tidak terjadi hilangya generasi penerus bangsa yang terdidik, cerdik dan memiliki daya saing secara global, demi terus menjaga eksistensi bangsa dengan memegang teguh cita-cita luhur bangsa indonesia. Hal ini yang harus menjadi karakter pemuda bangsa indonesia. Prilaku baiknya tidak dibuat-buat melainkan alami muncul dari diri seseorang ketika harus menyikapi suatu keadaan (Mulyasa, 2012).

Merunut bahwa generasi muda merupakan tonggak eksistensi bangsa kedepan, yang juga merupakan investasi bangsa yang berharga organisasi 'Aisyiyah merasa terpanggil untuk ikut serta dalam menyiapkan generasi muda yang unggul, cerdik dan berdaya saing global secara dini.

'Aisyiyah yang telah berkiprah mulai dari19 Mei 1917 (www_aisyiyah.or.id), yang artinya bahwa 'Aisyiyah sudah menempuh abad kedua telah melihat bahwa generasi muda khususnya anak usia dini sebagai potensi unggul dimasa depan. Kesadaran itu kemudian mendorong 'Aisyiyah untuk mendirikan taman kanak-kanak pada 1919, dengan memperkenalkan Froebel Kindergarten 'Aisyiyah, sebagai sekolah anak-anak yang pertama kali dimiliki oleh pribumi di masa penjajahan belanda.

Sejalan dengan perkembangan Zaman, nama lembaga tersebut diganti menjadi Taman Kanak-Kanak 'Aisyiyah Bustanul Athfal atau yang lebih dikenal dengan TK ABA (Siti Dalilah Candrawati, Rubrik Opini Majalah Walida, April-Mei 2015). 
HISTORIA: Jurnal Program Studi Pendidikan Sejarah Volume 7 (2) 2019

ISSN 2337-4713 (E-ISSN 2442-8728)

Taman kanak-kanak sendiri secara umum dimaknai sebagai suatu bentuk satuan pendidikan anak usia dini pada jalur formal yang diselenggarakan bagi anak usia 4-6 tahun (Suyadi,2010:18). Keberadaan TK dapat membantu anak menemukan peer group atau teman sebaya mereka, sehingga kemampuan sosial anak dapat berkembang (Nusa Putra, 2012:57). Merujuk pada pengertian tersebut, maka taman kanak-kanak merupakan pendidikan formal bagi anak usia 4-6 tahun dimana dengan pendidikan ini, anak akan dibantu untuk mengembangkan kemampuan sosialnya karena akan belajar berinteraksi dengan orang diluar keluarga. Dengan modal ini, anak diharapkan mampu berkembang dengan baik dimasa yang akan datang.

Taman kanak-kanak yang ada saat ini dibagi menjadi dua, taman kanakkanak negeri yang didirikan oleh pemerintah dan taman kanak-kanak swasta yang didirikan oleh masyarakat, yang salah satunya adalah TK 'Aisyiyah Bustanul Athfal.

Saat ini perjalanan TK 'Aisyiyah Bustanul Athfal sudah masuk pada abad yang kedua. Sudah muncul ratusan bahkan ribuan TK 'Aisyiyah Bustanul Athfal yang ada di Indonesia. Perjalanan yang dapat dikatakan cukup panjang karena telah menempuh perjalan lebih dari satu abad. Meski demikian tantangan yang muncul terus berganti sesuai dengan perkembangan zaman. Tidak hanya sekedar memperbaiki secara kuantitas, namun juga secara kualitas perlu mendapat perhatian khusus. Hal ini salah satunya dapat diatasi dengan berkaca atau belajar dari diri sendiri di masa lampau atau belajar dari sejarah. Artinya perbaikan melihat dari sejarah perjalanan TK 'Aisyiyah Bustanul Athfal sebelumnya. Hal ini sesuai dengan fungsi ilmu sejarah secara edukatif. Menurut pendapat Louis (1986) belajar dari sejarah dapat memberikan gambaran masa lalu yang kemudian dapat dijadikan pedoman dimasa yang akan datang.

Perkembanganya, hingga saat ini belum ada secara lengkap data tentang sejarah TK 'Aisyiyah Bustanul Athfal di Provinsi Lampung sehingga belum dapat diambil pelajaran atau ibrohnya sebagai pijakan untuk perbaikan di masa yang akan datang. Untuk itu perlu adanya penelitian tentang sejarah TK 'Aisyiyah Bustanul Athfal yang pada awalnya terfokus pada TK 'Aisyiyah Bustanul Athfal terbaik dan tertua di Provinsi Lampung.

Hal ini penting dilakukan karena apabila perkembangan TK 'Aisyiyah Bustanul Athfal tidak terdokumentasikan dengan baik maka akan dapat menjadi penghambat rantai komunikasi yang menuntut berkesinambungan. Perlu 
adanya fondasi sejarah yang kuat jika ingin maju dan menjadi besar. Sejarah akan mengarahkan gerak menuju tujuan yang jelas. Karena tujuan awal pembentukkan tentu menuntut untuk terus dilanjutkan, dan kelanjutan tujuan dari semula dapat terlaksana jika dapat terdokumentasikan dengan baik.

Oleh karenanya perlu adanya data sejarah yang ilmiah untuk dapat menggambarkan kondisi sejarah TK 'Aisyiyah Bustanul Athfal di Provinsi Lampung sebagai upaya menjaga komunikasi yang berkesinambungan antar lini masa. Untuk memenuhi kebutuhan itu, maka dilakukan penelitian tentang TK 'Aisyiyah Bustanul Athfal yang pada tahap awal ini baru TK 'Aisyiyah Bustanul Athfal Tertua dan terbaik di Provisni Lampung.

Secara spesifik, Penulisan ini bertujuan untuk mengetahui secara historis apa yang menjadi latarbelakang pendirian TK 'Aisyiyah Bustanul Athfal tertua dan terbaik di Provinsi Lampung. Selain itu yang ingin dipaparkan dalam penulisan ini adalah bagaimana strategi yang digunakan oleh TK 'Aisyiyah Bustanul Athfal untuk mempertahankan keberadaan TK 'Aisyiyah Bustanul Athfal hingga saat ini dan menjadi TK 'Aisyiyah Bustanul Athfal unggulan/terbaik di Provinsi Lampung.
METODE

Penelitian yang dilakukan
menggunakan metode penelitian
sejarah. Metode sejarah, menurut Louis (1986:32), dapat dipahami sebagai proses untuk menguji dan menganalisis secara kritis rekaman dan peninggalan masa lalu, yang identik dengan sumber sejarah. Metode sejarah juga diartikan sebagai petunjuk pelaksanaan dan petunjuk teknis tentang bahan, kritik, interpretasi, dan penyajian sejarah (Kuntowijoyo, 2003: xix). Menulis sejarah dengan teknik yang benar dapat dilakukan pada berbagai topik terutama pada pembahasan yang bernilai sejarah (Bobi, 2016:12).

Dalam kajian penelitian ini, penulis sepenuhnya mengikuti metode sejarah yang terdiri atas empat langkah pokok utama yaitu:

\section{Heuristik}

Heuristik adalah teknik atau caracara untuk menemukan sumber yang bisa didapat melalui studi kepustakaan, pengamatan secara langsung di lapangan atau melalui interview (Alian, 2012:9-10). Heuristik merupakan pengumpulan sumber-sumber sejarah yang berisi data-data sejarah sesuai dengan obyek penelitian. Implementasi metode heuristik pada penelitian ini adalah untuk mencari data tentang masalah penelitian, seperti 
HISTORIA: Jurnal Program Studi Pendidikan Sejarah Volume 7 (2) 2019

ISSN 2337-4713 (E-ISSN 2442-8728)

pengumpulan dokumen-dokumen yang ada di lokasi penelitian. Selain itu, wawancara juga dilakukan kepada tokoh pendiri TK 'Aisyiyah Bustanul Athfal yang ada dan masih hidup guna menggali informasi sesuai dengan data penelitian yang dibutuhkan.

\section{Kritik sumber}

Kritik sumber pada penelitian sejarah dibagi menjadi dua, kritik ekstern dan kritik intern. Kritik ekstern adalah untuk menyelidiki keaslian sumber dengan menjawab pertanyaan-pertanyaan $\quad 5 \mathrm{~W}+1 \mathrm{H}$. Sedangkan kritik intern adalah penentuan dapat tidaknya keterangan dalam dokumen digunakan sebagai fakta sejarah (Marzuki, 2004:35).

Implementasi langkah ini dalam penelitian digunakan untuk menilai atau menyeleksi keaslian dokumen yang diperoleh, baik berupa buku, foto-foto, manuskrip atau dokumendokumen lain yang ditemukan pada saat penelitian.

\section{Interpretasi}

Interpretasi merupakan penafsiran terhadap fakta-fakta sejarah sebagai hasil dari langkah sebelumnya yaitu kritik sumber. Melalui interpretasi maka akan dijabarkan dan dimaknai data penelitian yang nantinya akan ditulis pada tahapan historiografi.
Implementasi interpretasi dalam penelitian ini adalah memberikan makna terhadap data penelitian baik yang berupa dokumen, hasil wawancara maupun hasil dari observasi.

\section{Historiografi}

Historiografi merupakan langkah terakhir dalam sebuah penelitian sejarah. Melakukan penulisan sejarah menjadi sarana mengkomunikasikan hasil-hasil penelitian yang diungkap, di uji (verifikasi) dan diinterpretasi merupakan langkah terakhir dalam penelitian sejarah (Daliman.2012). Ketika sejarawan memasuki tahapan menulis, maka ia mengerahkan seluruh daya pikiranya, bukan saja keterampilan teknis menggunakan pikiran-pikiran kritis dan analisisnya karena ia pada akhirnya harus menghasilkan suatu sintesis dari seluruh hasil penelitian atau penemuan itu dalam suatu penulisan yang utuh (Helius, 2007:121).

Untuk mendukung implementasi metode sejarah terlaksana dengan baik, perlu adanya teknik pengumpulan data yang tepat. Adapun teknik pengumpulan data yang digunakan antara lain wawancara mendalam, observasi lapangan secara langsung, dan pencatatan dokumen. Berikut bagan alur penelitian. 


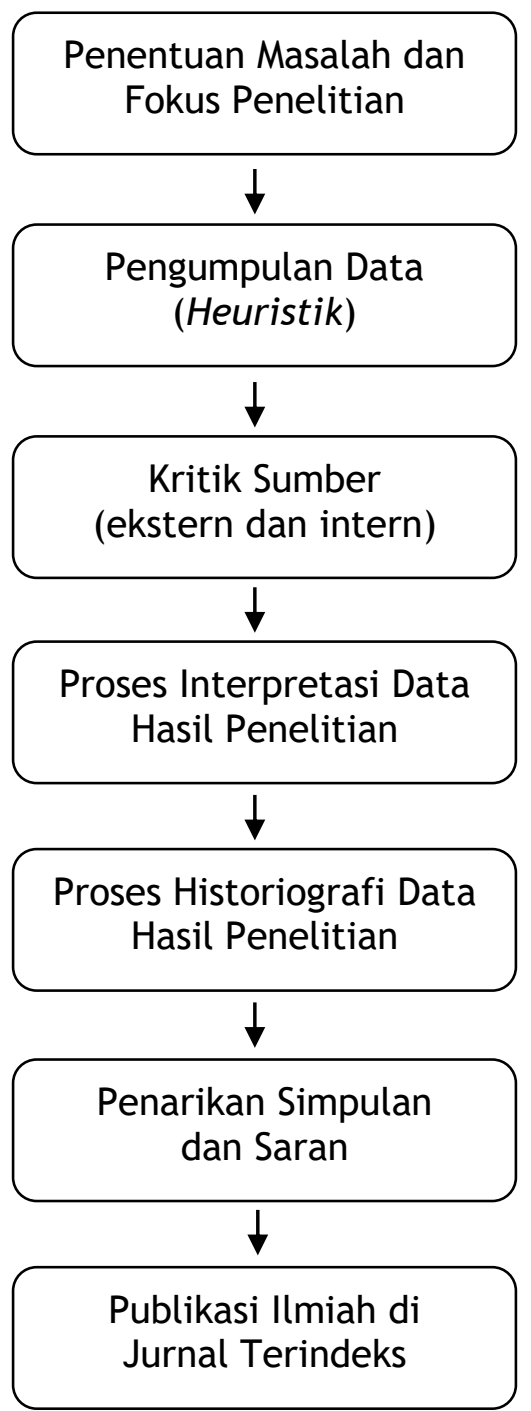

Gambar 1. Alur penelitian

\section{HASIL DAN PEMBAHASAN}

Penelitian ini dibagi menjadi dua bagian yaitu tinjauan historis TK 'Aisyiyah Bustanul Athfal tertua dan tinjauan historis TK 'Aisyiyah Bustanul Athfal terbaik/unggulan di Provinsi Lampung. Pokok-pokok kajian yang mendasarinya sama, namun temuanya tentu berbeda karena berada dalam kondisi yang berbeda.

TK 'Aisyiyah Bustanul Athfal tertua di Provinsi Lampung
Berawal dari perhatian Ahmad Dahlan terhadap nasib kaum perempuan terutama di wilayah Kauman. Dibentuklah sebuah wadah kelompok pengajian bagi para pekerja perempuan yang mayoritas buruh pada industri batik dengan diberi nama Sapa Tresna. Tujuannya agar perempuan mampu untuk membaca, menulis dan mempelajari Islam.

Pada 27 Rajab 1335 H bertepatan dengan 19 Mei 1917 M Aisyiyah sebuah gerakan perempuan Islam berkemajuan didirikan di Kauman Yogyakarta. Sebagai bagian dari Muhammadiyah, Aisyiyah tidak terlepas dari campurtangan $\mathrm{KH}$. Ahmad Dahlan. Perkembangan Aisyiyah pesat mengikuti gerak maju Muhammadiyah. Pada 1919 telah muncul TK (Taman Kanak) Frobel untuk anakanak sekitar Kauman. Catatan lain mengungkapkan pada 1924 baru terbentuk Taman kanak-kanak sebagai embrio dari TK 'Aisiyah Busthanul Athfal yang didirikan oleh Siti Umniyah dan rekan-rkannya (Mu'arif, Setyowati, 2014). Pada tahun 1934 Aisyiyah telah di bentuk di Teluk Betung Lampung. Perlahan berkembang dan menunjukan eksistensinya hingga saat ini.

Merujuk dari data Pimpinan Wilayah 'Aisyiyah Provinsi Lampung, menunjukkan bahwa TK 'Aisyiyah Bustanul Athfal tertua terletak di teluk betung selatan yaitu TK 'Aisyiyah Bustanul Athfal Teluk Betung Selatan. 
HISTORIA: Jurnal Program Studi Pendidikan Sejarah Volume 7 (2) 2019

ISSN 2337-4713 (E-ISSN 2442-8728)

TK 'Aisyiyah Bustanul Athfal Teluk Betung Selatan didirikan pada Januari 1955 oleh Pimpinan Cabang 'Aisyiyah yang telah berdiri sebelumnya yaitu pada tahun 1934. Latarbelakang berdirinya TK ini bermula dari kebutuhan masyarakat akan pendidikan taman kanak-kanak yang pada masa itu Belum ada sekolah TK yang berdiri di Teluk Betung Selatan. TK 'Aisyiyah Bustanul Athfal inilah yang kemudian menjadi perintis dari pendidikan anak di wilayah itu.

Perkembanganya, kemudian TK ini dikukuhkan oleh Depdikbud pada tahun 1961. Sementara itu, surat tanda terdaftar dikeluarkan oleh pimpinan pusat Aisyiyah Jakarta bernomor 29 tertanggal 06 Juni 1963 yang ditangdatangani oleh Siti Fatimah sebagai ketua dan Siti Fatimah Usulu sebagai sekretaris pimpinan pusat Aisyiyah seksi pengajaran.

Pemrakarsa TK 'Aisyiyah Bustanul Athfal di Teluk Betung selatan adalah Ibu Zalenah sebagai bagian dari pengurus PC Aisyiyah Teluk Betung. Ketika pendirian diresmikan oleh Gele Harun yang pada saat itu sebagai Residen Lampung dan masih belum ada sekolah TK yang berdiri di Teluk Betung Selatan. TK 'Aisyiyah Bustanul Athfal inilah yang kemudian menjadi perintis dari pendidikan anak. Pada awal berdirinya belum ada perijinan kepada dinas atau instansi resmi, baru pada tahun 1961 kemudian diberikan ijin penyelenggaraan TK 'Aisyiyah Bustanul Athfal dengan nomor surat: A.11.7813/I.12/T/1988.

TK 'Aisyiyah Bustanul Athfal Teluk Betung selatan didirikan pada sebidang tanah seluas 747,25 $\mathrm{M}^{2}$. Tanah tersebut merupakan wakaf dari salah satu anggota Muhammadiyah keturunan Arab bernama Toyib Babakhe. Masyarakat sekitar mengambut baik keberadaan TK 'Aisyiyah Bustanul Athfal Teluk Betung selatan namun seiring berjalannya waktu banyak persaingan dari TK yang lain. Selain itu ada perselisihan masyarakat yang takut dengan Muhammadiyah (kalangan tradisionalis).

Pada awal terbentuknya TK 'Aisyiyah Bustanul Athfal Teluk Betung selatan banyak dukungan dari berbagai pihak termasuk kalangan pemerintah karena banyak dari mereka adalah anggota atau simpatisan Muhammadiyah.

Struktur oraganisasi berdasarkan hasil wawancara dengan pengurus PC 'Aisyiyah Teluk Betung Selatan dan Tenaga Pengajar di TK Aisiyah serta penelusuran seumber didapatkan data sebagai berikut.

1. 1955-1980 (belum diketahui)

2. Arni periode 1980-1984

3. Eliyanara periode 1984-1997

4. Aminah S.Ag periode 1997-2005

5. Satunah 2005-2010)

6. Rini Setiawati, S.Pd (2010-sekarang) 


\section{Kurikulum TK}

Kurikulum yang diterapkan diawal menekankan pada keagamaan, seperti belajar doa, tatacara sholat, selain kegiatan pembelajaran yang lainnya. Pada Awal Berdiri lebih memberikan Pelajaran yang menjadi ciri khas belajar hafalan Al Quran (surat-surat pendek), tatacara/praktek sholat, doa-doa, praktek wudhu, unsur-unsur keagamaan lebih banyak diajarkan pada waktu awal berdiri. Adanya tuntutan dari pemerintah TK 'Aisyiyah Bustanul Athfal saat ini telah menyesuiakan dalam pengunaan kurikulum 2013.

TK 'Aisyiyah Bustanul Athfal Teluk Betung Selatan memiliki Program unggulan periode awal di adalah menekankan pada ajaran keagaman (islam) hanya saja seiring perkembangan zaman TK 'Aisyiyah Bustanul Athfal Teluk Betung selatan kemudian mengadakan berbagai fasilitas untuk menarik simpati Peserta Didik untuk sekolah di TK 'Aisyiyah Bustanul Athfal seperti Drumband. Banyak kegiatan yang diikuti dan memiliki prestasi yang unggul daripada TK lainnya.

\section{TK 'Aisyiyah Bustanul Athfal terbaik di Provinsi Lampung}

Berdasarkan data dari lapangan TK 'Aisyiyah Bustanul Athfal 1 Pringsewu menjadi TK 'Aisyiyah Bustanul Athfal terbaik/unggulan di Provinsi Lampung. TK ini didirikan pada tanggal 1 maret
1961 (Tahun 1988 sesuai dengan surat izin pendirian taman kanak-kanak Depertemen Pendidikan dan Kebudayaan Kantor Wilayah Provinsi Lampung, tahun 1998 sesuai dengan surat izin pendirian taman kanak-kanak Depertemen Pendidikan dan Kebudayaan Kantor Wilayah Provinsi Lampung Kantor Kabupaten Tanggamus, tahun 2004 sesuai dengan Surat Izin Pendirian dari Dinas Pendidikan Kabupaten Tanggamus), namun pada surat tanda terdaftar tahun 1978 didirikan pada tanggal 1 mei 1961. Hal ini sesuai dengan Surat Tanda Terdaftar Pimpinan Pusat 'Aisyiyah Bagian Pendidikan dan Pengajaran.

Pemrakarsa berdirinya TK 'Aisyiyah Bustanul Athfal 1 Pringsewu adalah ibu-ibu pengurus Aisyiyah Pringsewu yang terdiri dari lbu Syamsidar alias Ibu Manggung, Ibu Darsono, Ibu $\mathrm{Hj}$. Wanis dan Bapak Suja'i. Prasarana yang dimiliki oleh TK ketika pertama berdiri diantaranya:

1. Gedung (ruang belajar)

2. Alat Peraga Edukatif (APE) yaitu kelengkapan belajar anak sederhana berupa alas untuk duduk, dan beberapa mainan anak-anak sebagai penopang kegiatan belajar seperti ayunan dan prosotan.

TK 'Aisyiyah Bustanul Athfal 1 Pringsewu berdiri atas dorongan dari masyarakat karena diperlukan 
HISTORIA: Jurnal Program Studi Pendidikan Sejarah Volume 7 (2) 2019

ISSN 2337-4713 (E-ISSN 2442-8728)

pendidikan anak-anak pada masa itu. Hal ini dibuktikan dengan baru hanya ada 1 TK yaitu TK Xaverius Pringsewu yang kapasitasnya juga terbatas. Selain itu, TK yang ada juga berbasis non muslim sehingga mendorong untuk segera diwujudkan TK yang bernuansa Islam di Wilayah Pringsewu.

Berdirinya TK 'Aisyiyah Bustanul Athfal 1 Pringsewu disambut antusias oleh masyarakat sekitar, karena dengan adanya TK 'Aisyiyah Bustanul Athfal dapat memfasilitasi kebutuhan pendidikan anak khususnya anak-anak masyarakat Pringsewu yang beragama Islam. Reaksi masyarakat sekitar terhadap keberadaan 'Aisyiyah saat itu sangat mendukung dengan antusias diwujudkan dengan memberikan bantuan berupa donasi baik materi maupun tenaga dalam kegiatan gotong royong pembangunan TK.

Kepala sekolah yang pernah memimpin TK 'Aisyiyah Bustanul Athfal 1 Pringsewu antara lain:
a. Ibu Tim
(Periode 1961- 1978)
b. Kusiyati
(Periode 1978- 1984)
c. Widyowati
(Periode 1984- 1992)
d. Supriyati,S.Pd. (Periode 1992- 2001)
e. Nur Umilah, A.Ma (Periode 2001- 2010)
f. Andriani, S.Pd. (Periode 2010- 2018)
g. Estiasih, S.Pd. (Periode 2018- sekarang)

\section{Manajemen/Administrasi Sekolahan}

\section{a. Pengeloaan Pembelajaran}

Pembelajaran yang dilaksanakan di TK 'Aisyiyah Bustanul Athfal 1 Pringsewu menggunakan Kurikulum 2013 yang telah disusun dan disesuaikan dengan kondisi peserta didik. Kurikulum disusun melalui workshop dengan membentuk tim penyusun yang selanjutnya dilakukan pengembangan kurikulum. Penyusunan kurikulum mengacu pada UU No 20 tahun 2003 tentang Sisdiknas, Permendiknas Nomor 146 tahun 2014 tentang Kurikulum Pendidikan Anak Usia Dini dan Permendiknas No 137 tahun 2014 tentang Standar Pendidikan Anak Usia Dini. Sejak tahun 2015 pembelajaran sudah menggunakan sentra.

TK 'Aisyiyah Bustanul Athfal 1 Pringsewu mengajarkan mata pelajaran antara lain mata pelajaran mengenalkan huruf hijaiyah, menghafal surat-surat pendek dalam Al Qur'an, hafalan do'a sehari-hari, praktik wudhu dan sholat, dan pendidikan jasmani berupa gerak dan lagu. Kegiatan di sekolah diantaranya kegiatan intrakurikuler meliputi belajar sholat, membaca Iqro', hafalan surat-surat pendek, hafalan 
do'a dan hadits sehari-hari. Sedangkan kegiatan ekstra kurikuler meliputi kegiatan menyanyi dan belajar tentang sajak. Adapun program unggulan TK 'Aisyiyah Bustanul Athfal 1 Pringsewu adalah hafalan surat pendek, praktik sholat dan praktik wudhu

\section{b. Ketenagaan}

TK 'Aisyiyah Bustanul Athfal 1 Pringsewu dipimpin oleh 1 kepala sekolah, memiliki 16 orang guru dan 1 cleaning servis. Pelaksanaanya dibantu oleh Ketua Komite sekolah serta dibimbing dan dipandu oleh Pimpinan Cabang Aisyiyah setempat

\section{c. Pengadaan Sarana dan Prasarana}

Kelengkapan sarana dan prasarana TK 'Aisyiyah Bustanul Athfal 1 Pringsewu berasal dari sumbangsih pengurus Aisyiyah setempat. Peruntukanya sebenarnya tidak hanya untuk sekolah ini saja melainkan sekolah TK lainya yang masih dibawah kepengurusan yang sama yaitu 'Aisyiyah. Sedangkan pemeliharaanya dilakukan secara mandiri dan berkala sesuai dengan kebutuhan.

\section{d. Sumber Pendanaan}

TK 'Aisyiyah Bustanul Athfal 1 Pringsewu memperoleh sumber dana sebagai biaya untuk beroperasi berasal dari tiga sumber.
1. Berasal dari wali murid (bangunan dan SPP serta biaya lainya yang bersifat insidental)

2. Bantuan dari pemerintah berupa Biaya Operasional Penyelenggara (BOP)

3. Bantuan dari pengurus Aisyiyah setempat

Pada dasarnya TK 'Aisyiyah Bustanul Athfal 1 Pringsewu merupakan TK induk yang memiliki 2 cabang yang dalam pengelolaanya dikelola oleh satu kepengurusan dan saling mensubsidi antara sekolah yang satu dengan sekolah lainya.

\section{e. Partisipasi Masyarakat Sekitar}

Masyarakat berperan aktif dan mendukung kegiatan yang dilaksanakan oleh TK 'Aisyiyah Bustanul Athfal 1 Pringsewu. Bentuk dukunganya adalah munculnya peralatan drumband yang dapat digunakan oleh anak-anak TK sebagai kegiatan tambahan. Selain itu, wali murid juga berpartisipasi aktif pada saat pertemuan-pertemuan yang dilaksanakan oleh TK 'Aisyiyah Bustanul Athfal 1 Pringsewu sebagai bentuk komunikasi sekolah dengan wali murid.

\section{f. Pengelolaan Kegiatan \\ Ektrakurikuler}

Pelaksanaan kegiatan ekstrakurikuler dikelola langsung oleh guru setempat dan tidak melibatkan pihak luar. Kegiatan ektrakurikuler yang 
HISTORIA: Jurnal Program Studi Pendidikan Sejarah Volume 7 (2) 2019

ISSN 2337-4713 (E-ISSN 2442-8728)

ada diantaranya adalah Drumband dan menari. Selain itu ada juga kegiatan unggulan dari TK 'Aisyiyah Bustanul Athfal 1 Pringsewu adalah Tahfid Qur'an dan belajar menjadi Da'l serta belajar teknik dasar tapak suci.

\section{PENUTUP}

\section{Simpulan}

Berdasarkan hasil penelitian yang dilakukan terhadap TK 'Aisyiyah Bustanul Athfal tertua dan tebaik di Provinsi Lampung dapat disimpulkan bahwa TK 'Aisyiyah Bustanul Athfal tertua di Provinsi Lampung terletak di daerah Teluk Betung Selatan yaitu TK 'Aisyiyah Bustanul Athfal Teluk Betung Selatan yang bediri pada tahun 1955. Sedangkan TK 'Aisyiyah Bustanul Athfal terbaik di Provinsi Lampung terletak di daerah Pringsewu yaitu TK 'Aisyiyah Bustanul Athfal 1 Pringsewu.

Latarbelakang pendirian TK
'Aisyiyah Bustanul Athfal adalah
kebutuhan adanya lembaga pendidikan
bagi anak pada masa itu yang masih
sangat terbatas, dan kalaupun ada
belum bernuansa islam. Inisiator
pendirianya adalah ibu-ibu pengurus
'Aisyiyah yang memang sudah lebih dulu
berdiri dan berkembang. Awal
pengelolaanya dilakukan dengan cara
swadaya masyarakat sekitar karena
menyambut antusias upaya mendirikan
sekolah tersebut. Hingga saat ini dengan

berbagai upaya yang dilakukan sekolah termasuk dengan membuat program unggulan, TK 'Aisyiyah Bustanul Athfal tertua dan terbaik di Provinsi Lampung masih eksis berdiri dengan jumlah siswa dan guru yang terus berkembang

\section{Saran}

Berdasarkan hasil temuan penelitian, maka peneliti dapat memberikan saran antara lain:

1. Sekolah disarankan untuk dapat mengarsipkan semua kegiatan yang dilakukan oleh sekolah selain berguna untuk kelengkapan akreditasi, juga dapat berguna untuk penelitian lain yang serupa jika akan melakukan penelitian di sekolah tersebut.

2. Bagi Pimpinan Wilayah 'Aisyiyah Provinsi Lampung untuk dapat melakukan pembinaan sekolah TK ABA yang lainya merujuk pada sekolah TK ABA terbaik di provinsi lampung untuk lebih memacu peningkatan kualitas TK 'Aisyiyah.

3. Bagi peneliti lain, hasil penelitian ini dapat dijadikan rujukan untuk melakukan penelitian lain yang serupa serta dapat dijadikan pijakan awal penelitian yang akan dilakukan. 


\section{DAFTAR PUSTAKA}

Alian Sair. (2012). Metodologi Sejarah dan Historiografi. Palembang. Proyek SP4 Universitas Sriwijaya

Bobi Hidayat. (2016). Aplikasi Penulisan Sejarah Pada Mata Kuliah Sejarah Sosial Historia: Jurnal Pembelajaran Sejarah dan Sejarah UM Metro. Vol 4 nomor 1 halaman 12

Daliman. (2012). Metode Penelitian Sejarah.Yogyakarta. Ombak

H.A.R. Tilaar. (2012). Perubahan Sosial dan Pendidikan. Jakarta. Rineka Cipta

Helius Sjamsuddin. (2007). Metodologi Sejarah. Yogyakarta. Ombak

H.E. Mulyasa. (2012). Manajemen Pendidikan Karakter. Jakarta. Bumi Aksara

Kuntowijoyo. (2003). Metodologi Sejarah. Yogyakarta. PT Tiara Wacana Yogya

Louis Gottschalk. (1986). Mengerti Sejarah. Jakarta. Universitas Indonesia

Marzuki Yass. (2004). Metodologi Sejarah dan Historiografi. Palembang. Proyek SP4 Universitas Sriwijaya

Nusa Putra dan Ninin Dwi Lestari. (2012). Penelitian Kualitatif PAUD. Jakarta. PT Raja Grafindo

Siti Dalillah Candrawati. (2015). Rubrik Opini Majalah Walida April-Mei 2015. Surabaya. PWA Jawa Timur

Suyadi. (2010). Psikologi Belajar Anak Usia Dini. Yogyakarta. Pedagogia

Mu'arif, Setyowati. (2014). Srikandisrikandi Aisyiyah. Suara Muhammadiyah. Yogyakarta.

\section{Sumber Wawancara}

1. Hj. Mariam binti Nazar Hanif (Ketua Pimpinan Cabang 'Aisyiyah Teluk Betung Selatan)

2. Rini Setiowati, S.Pd. (Kepala Sekolah TK 'Aisyiyah Bustanul Athfal 1 Teluk Betung Selatan)

3. Ibu-ibu pengurus 'Aisyiyah TK 'Aisyiyah Bustanul Athfal 1 Pring Sewu

4. Esti Asih, S.Pd. (Kepala Sekolah TK 'Aisyiyah Bustanul Athfal 1 Pring Sewu) 